\title{
Correction to: Genome and transcriptome of the natural isopropanol producer Clostridium beijerinckii DSM6423
}

Hadrien Máté de Gérando ${ }^{1,2}$, François Wasels², Angélique Bisson², Benjamin Clement², Frédérique Bidard², Etienne Jourdier ${ }^{2}$, Ana María López-Contreras ${ }^{1}$ and Nicolas Lopes Ferreira ${ }^{2 *}$

\section{Correction}

Following the publication of this article [1], the authors noticed that Figs. 2, 3 and 4 were in the incorrect order and thus had incorrect captions. The images that were incorrectly published as Figs. 2, 3 and 4 should have been published as Figs. 3, 4 and 2 respectively.

The correct versions of Figs. 2, 3 and 4 with captions have been included in this Correction.

The original article has been corrected.

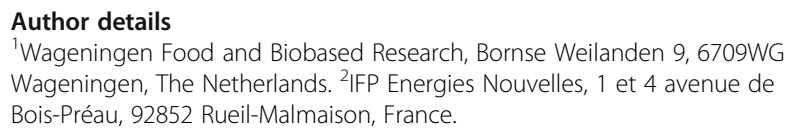

\section{Reference}

1. de Gérando M, et al. BMC Genomics. 2018:19:242.

\footnotetext{
* Correspondence: nicolas.lopes-ferreira@ifpen.fr

${ }^{2}$ IFP Energies Nouvelles, 1 et 4 avenue de Bois-Préau, 92852 Rueil-Malmaison,
} France

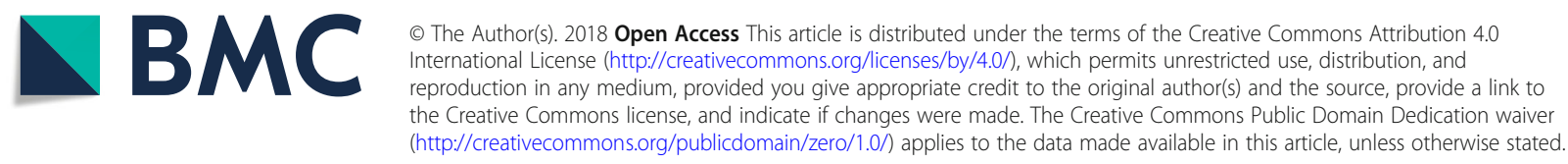



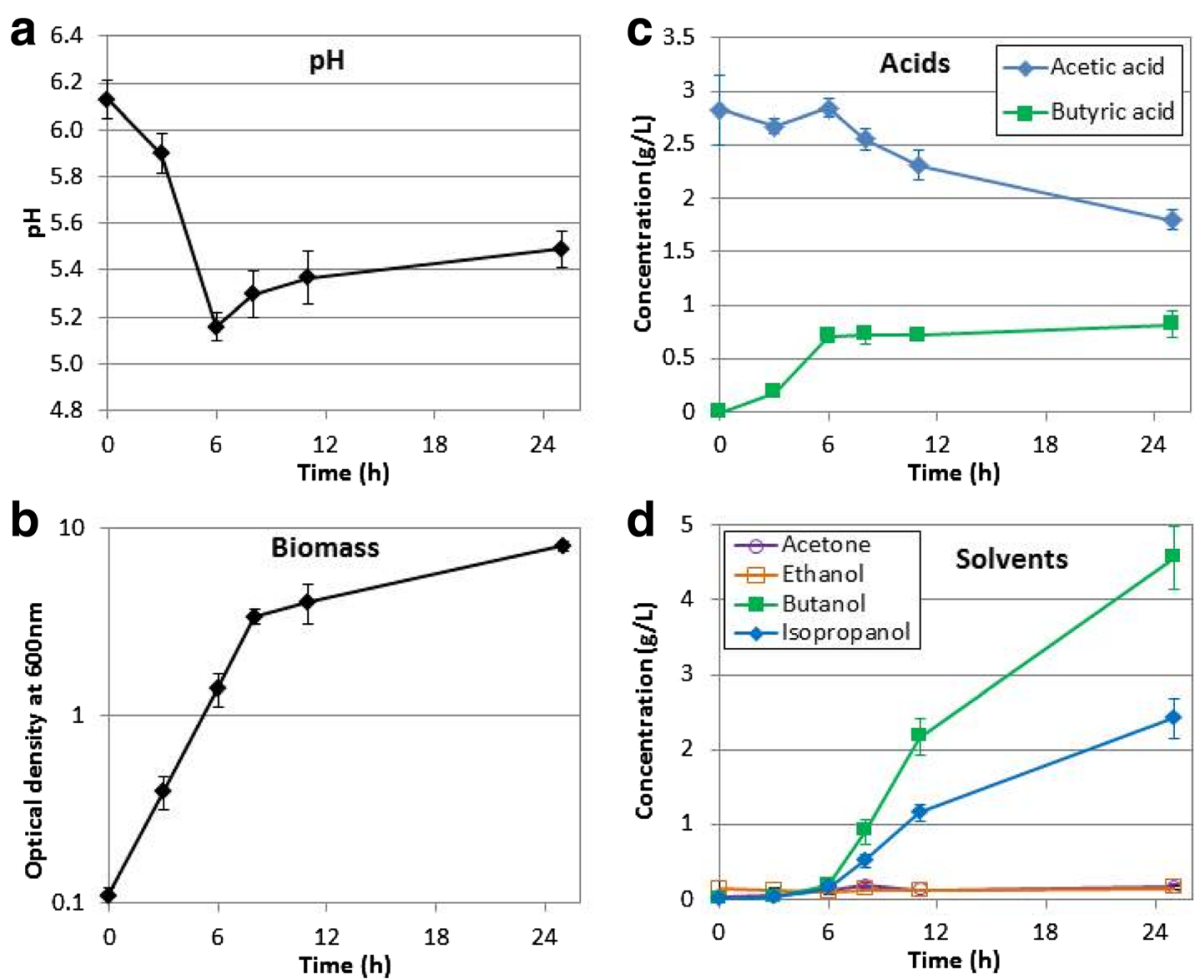

Fig. 2 Fermentation profile of Clostridium beijerinckii DSM 6423 on glucose. C. beijerinckii DSM 6423 was cultivated in bioreactors in GAPES medium. $\mathbf{a} \mathrm{pH}, \mathbf{b}$ biomass followed by $\mathrm{OD}_{600}, \mathbf{c}$ acids and $\mathbf{d}$ solvents. Values are the mean and standard deviation of the 6 biological replicates. See Additional file 3 for details on the biological replicates

a 1008 differentially expressed genes
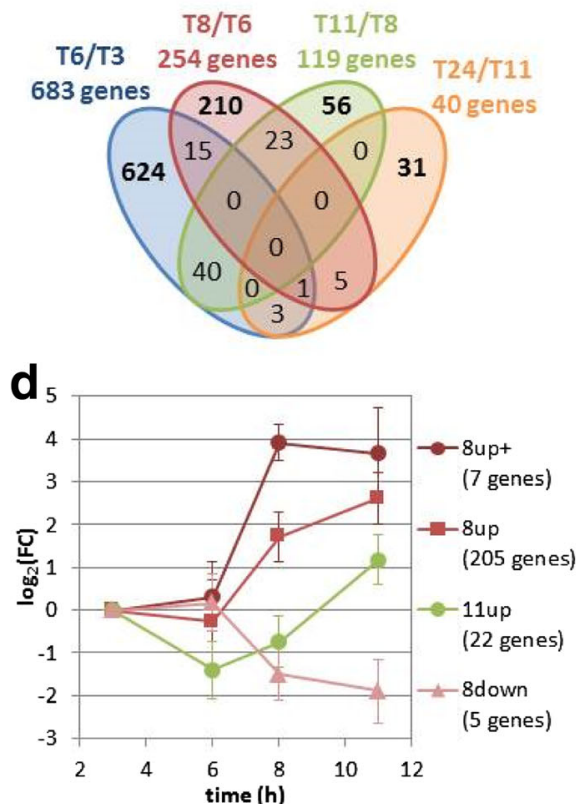
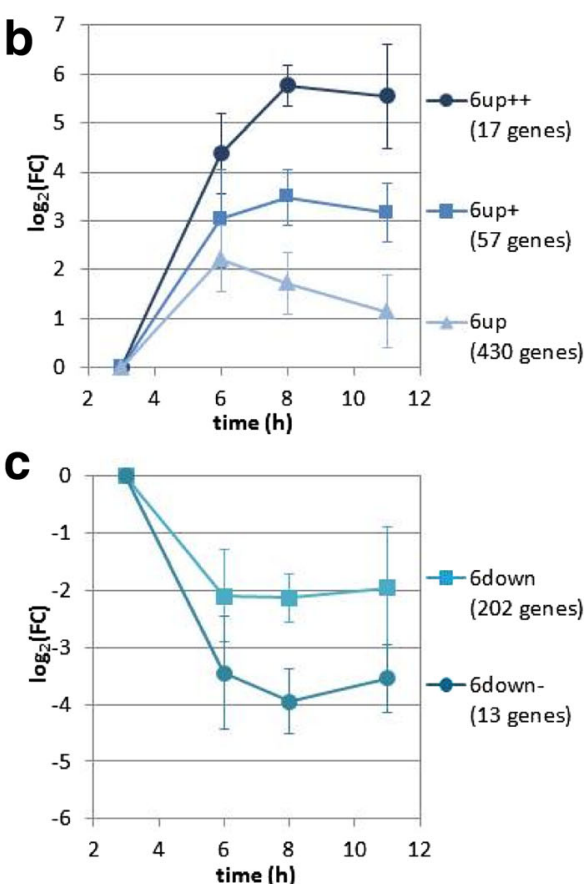

Fig. 3 Global transcriptomic analysis of C. beijerinckii DSM6423 fermentation on glucose. a Venn Diagram showing the number of genes regulated in various physiological time points. $\mathbf{b}$ to $\mathbf{d}$ : kinetic expression profiles of various clusters of genes: genes up-regulated at $6 \mathrm{~h} \mathbf{b}$, genes down-regulated at $6 \mathrm{~h} \mathbf{c}$, and genes regulated at $8 \mathrm{~h}$ or $11 \mathrm{~h} \mathbf{d}$ 


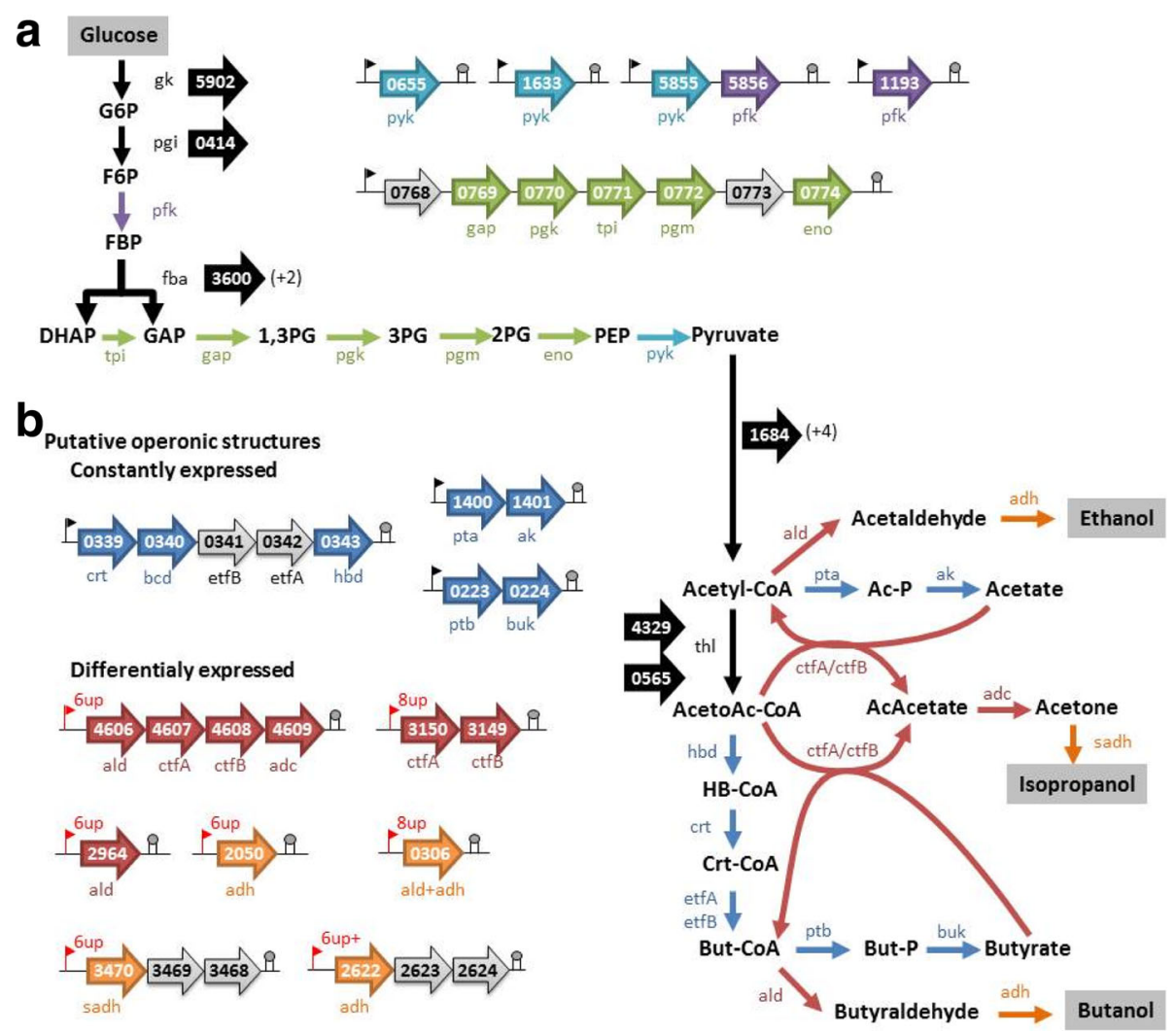

Fig. 4 Main genes and predicted operonic structures involved in the central metabolism of in C. beijerinckii DSM6423. a glycolysis; b acids and solvents production). Number of isozymes, predicted by Microscope tool (Genoscope, Evry, France) are indicated in brackets 